\title{
ПСИХОЛОГИЧЕСКИЕ АСПЕКТЫ ЗАЩИТЫ ЛИЧНОСТИ ОТ ВОЗДЕЙСТВИЯ НЕДОСТОВЕРНОЙ ИНФОРМАЦИИ
}

\section{PSYCHOLOGICAL ASPECTS OF PROTECTION OF PERSONALITY FROM THE EXPOSURE OF MISINFORMATION}

V. Latynov

Summary: The article analyzes the results of modern research on countering the dissemination of misinformation in the modern world and protecting an individual from its influence. The psychological mechanisms underlying the influence of such information on the consciousness of people are considered. The features of fake messages, contributing to their wide distribution, are highlighted. An assessment of the effectiveness of various strategies countering misinformation has been carried out. The factors that increase the effectiveness of the fight against misinformation are highlighted. Such factors include: the characteristics of the source of misinformation and the subject from which the refutation came, the structure of the refuting message, the topic it touches, the frequency of repetition of misinformation and the time elapsed between its appearance and refutation, the degree and direction of the cognitive activity of the recipient, his attitudes and beliefs.

Keywords: misinformation, fakes, conspiracy theories, refutation strategies, «mental model», cognitive activity.
$\mathrm{P}$ азвитие новых информационных технологий значительно облегчило распространение недостоверной информации и привело к внедрению в сознание многих людей несоответствующих реальности теорий и фактов, провоцирующих их на совершение дезадаптивных, наносящих вред себе и окружающим поступков. Степень распространения такого рода фактов и теорий в современном обществе приобретает угрожающие масштабы. Так, по данным опросов, половина жителей США являются сторонниками по крайней мере одной конспирологической теории [15].

Негативные последствия распространения недостоверной информации (как отдельных фактов, так и целых теорий, в частности, конспирологических) отмечаются в многих сферах общества. Фейковая информация способна влиять на имидж фирм, снижать авторитет политиков, приводить к негативным эффектам в области здравоохранения (отказ от вакцинизации и использование неэффективных способов лечения) [11].

Наличие указанных негативных эффектов делает актуальной проблему борьбы с недостоверной информацией. Ее решение невозможно без понимания того,
Латынов Владислав Викторович

К.nсх.н., С.н.С., ФГБУН Институт психологии Российской академии наук (Москва) vladlat5@lenta.ru

Аннотация: В статье проанализированы результаты современных исследований, касающихся противодействия распространению недостоверной (фейковой) информации в современном мире и защите личности от ее воздействия. Рассмотрены психологические механизмы, лежащие в основе влияния такой информации на сознание людей. Выделены особенности фейковых сообщений, способствующие их широкому распространению. Проведена оценка эффективности различных стратегий противодействия. Выявлены факторы, повышающие эффективность борьбы с недостоверной информацией. К такого рода факторам относятся: особенности источника недостоверной информации и субъекта, от которого исходило опровержение, структура опровергающего сообщения, затрагиваемая им тема, частота повторения недостоверной информации и время, прошедшее между ее появлением и опровержением, степень и направление когнитивной активности реципиента, его аттитюды и убеждения.

Ключевые слова: недостоверная информация, фейки, конспирологические теории, стратегии опровержения, «ментальная модель», когнитивная активность.

каковы причины появления и закономерности распространения такого рода информации; какие стратегии опровержения следует использовать в борьбе с ее распространением; при каких условиях эти стратегии оказываются наиболее эффективными. В последние годы проведено значительное количество психологических исследований, авторы которых постарались ответить на вышеуказанные вопросы. Мы в данной статье постараемся проанализировать и обобщить результаты этих исследований, последовательно останавливаясь на таких темах как механизмы появления ложных представлений о мире, закономерности распространения и способы борьбы с недостоверной информацией.

Прежде чем начинать борьбу с несоответствующими реальности фактами и теориями необходимо понять, почему они признаются истинными и встраиваются в картину мира человека. Исследования показали, что на склонность людей верить недостоверной информации влияют их личностные особенности. Так, признание людьми в качестве истинных различных конспирологических теорий сочеталось с наличием у них таких личностных черт как открытость опыту, враждебность и подозрительность по отношению к окружающим, тре- 
вожность и неуверенность [10; 16].

Установлено, что не существует одного единственного личностного основания предрасположенности к недостоверной информации. Обнаружено несколько констелляций личностных особенностей, связанных с принятием человеком несоответствующих реальности представлений [8]. Оказалось, что в зависимости от возраста, пола и конкретного вида конспирологической теории склонность к ним определяется различными чертами личности. Так, у более молодых людей склонность к таким теориям чаще связана с открытостью опыту, а в более позднем возрасте основным драйвером интереса к ним становятся враждебность и подозрительность. Кроме того, установлено, что для той или иной группы конспирологических теорий существует свой набор психологических предпосылок [15].

Помимо личностных характеристик на веру в несоответствующие реальности теории влияют социальнополитические и религиозные убеждения людей. Склонность к конспирологическим теориям оказалась связана с аномией, политическим радикализмом, авторитаризмом, религиозностью [12; 19; 21$]$.

Свой вклад в принятие недостоверной информации вносят и когнитивные механизмы функционирования психики. Чаще всего для их описания используется понятие «ментальных моделей» [3]. Как свидетельствуют исследования, человек не просто сохраняет поступающую к нему информацию об окружающем мире в виде набора разрозненных фактов, но строит на ее основе целостную и относительно непротиворечивую картину реальности [7]. Новая информация интегрируется в уже имеющийся у него образ мира, дополняя или уточняя его. Даже если такая информация потом признается недостоверной, ее «удаление» из картины мира оказывается непростой задачей. Простого указания на то, что тот или иной факт не соответствует реальности, как правило, бывает недостаточно, чтобы человек изменил свою ментальную модель. Для ее коррекции требуются как новые факты, так и обоснование необходимости исключения недостоверной информации из модели и замены ее на достоверную.

Для борьбы с несоответствующими реальности представлениями необходимо не только понимать психологические основания их принятия человеком, но также иметь представление о закономерностях их распространения в социуме. Как правило, обнаруживаются ощутимые различия в скорости и масштабах распространения достоверной и недостоверной информации [11]. Так, анализ 126000 новостей, размещенных в Твиттере в период с 2006 по 2017 гг., показал, что по сравнению с сообщениями, содержащие проверенные факты, фейки распространялись быстрее и охватывали более широ- кий круг пользователей [22]. Эти закономерности были особенно выражены в случае политических новостей, однако они выполнялись и в отношении таких тем как наука, финансы, природные катастрофы, терроризм. Кроме того, оказалось, что вопреки традиционному мнению о том, что так называемые «боты» выступают основными «разносчиками» фейковых новостей, различий между ними и реальными пользователями не было.

Подобная активность сетевого проникновения содержащих недостоверную информацию сообщений связана как с их характеристиками, так и с особенностями восприятия этих сообщений пользователями [11; 18]. Проведенный С. Восочи с соавт. анализ показал, что оценки новизны и оригинальности фейковых сообщений были выше, чем у сообщений, содержащих достоверную информацию [22]. А поскольку люди, как правило, более склонны распространять новую и оригинальную информацию [1], то неудивительным выглядит широкое распространение именно фейков. Кроме того, такие сообщения вызывали специфические эмоциональные реакции: удивление, страх и отвращение (для сообщений с достоверной информацией наиболее характерными были печаль и радость).

На распространение фейковой информации влияют также социально-демографические и индивидуальнопсихологические характеристики людей [2; 17]. Например, высокий уровень догматизма и низкая степень развития аналитических способностей благоприятствуют распространению такой информации [2].

Поскольку, как мы уже отмечали, интерес к недостоверной информации во многом «подпитывается» индивидуально-психологическими особенностями людей, то задача коррекции несоответствующих реальности представлений людей выглядит довольно непростой. И, действительно, даже в лабораторных условиях не всегда удается добиться желаемого эффекта. Нередко попытки изменения недостоверных представлений заканчиваются неудачей, а в отдельных случаях бывает и так, что сообщения, направленные на опровержение этих представлений, даже повышают уверенность людей в их истинности [14].

Однако, если оценить весь массив проведенных исследований, то сдержанный оптимизм в отношении перспектив борьбы с недостоверной информацией всетаки появляется. Результаты нескольких мета-анализов, затрагивающих данную проблему, показали, что при помощи специальных приемов можно весьма успешно ей противодействовать и корректировать представления людей в направлении их большей адекватности [5; 23].

Почему же, несмотря на позитивные результаты мета-анализов, мы все-таки говорим о сдержанном опти- 
мизме в отношении перспектив борьбы с недостоверной информацией. Дело в том, что исследования по ее опровержению бывают двух типов. В одних опровергается недостоверная информация в условиях придуманной, искусственно созданной ситуации («случившийся пожар был вызван наличием на складе взрывоопасных веществ, однако впоследствии оказалось, что причина пожара была иной»). В других же исследованиях используются реально существующие фейки (например, о серьезных негативных последствиях вакцинизации). Так вот, при сравнении эффективности борьбы с недостоверной информации в двух вышеуказанных типах ситуациях обнаруживаются существенные различия: искусственно сконструированная информация опровергается гораздо более успешно, чем реально существующий фейк [23]. Таким образом, борьба с распространением несоответствующих реальности представлений в реальной жизни оказывается весьма непростой задачей, нередко заканчивающейся неудачей.

Хотя результаты современных исследований и указывают на эффективность мероприятий по опровержению недостоверной информации, однако полностью нивелировать ее негативный эффект удается довольно редко. Так, мета-анализ результатов 32 исследований с общим числом участников в 6527 человек показал, что хотя опровержение и имело определенный эффект, делая представления людей более адекватными, однако их изначального уровня достоверности достичь все-таки не удавалось [24]. Т.о. даже несмотря на получение опровержения «след» от воздействия фейковой информации, проявляющийся в снижении достоверности представлений людей, все-таки оставался.

Проведенные исследования помимо ответа на вопрос об успешности борьбы с фейками позволили получить важные данные о том, при каких условиях она оказывается наиболее эффективной. Как оказалось, на ее эффективность влияли самые разные факторы: вид стратегии опровержения, особенности источника недостоверной информации и субъекта, от которого исходило опровержение, структура опровергающего сообщения, затрагиваемая им тема, частота повторения недостоверной информации и время, прошедшее между ее появлением и опровержением, степень и направление когнитивной активности реципиента, его аттитюды и убеждения [5; 23; 24].

Рассмотрим последовательно, каким именно образом вышеуказанные факторы влияли на эффективность опровержения. Одним из значимых в данном отношении факторов является вид стратегии, используемой для коррекции недостоверной информации [23]. Как правило, люди, оценивая истинность поступившей к ним информации, пытаются ответить для себя на следующие вопросы: Соответствует ли новая информация их пред- ставлениям? Нет ли в содержащем ее сообщении внутренних противоречий? Следует ли доверять источнику, от которого пришло сообщение? Считают ли другие люди эту информацию достоверной? [13].

С опорой на вышеуказанные данные об основных направлениях проверки личностью достоверности были разработаны стратегии борьбы с фейковой информацией. Наиболее часто используются такие из них, как консенсус (указание на единодушие специалистов по вопросу, истинность которого ставится под сомнением вновь появившимся фейком), взаимосвязанность (объяснение того, как и почему появился конкретный фейк), апелляция к кредитности источника (указание на то, что пользующиеся доверием и компетентные лица или организации считают фейковое сообщение ложным), факт-чекинг (ссылка на специальные сайты, содержащие оценки достоверности различных фактов, появляющихся в СМИ и социальных сетях), предупреждение (подчеркивание того, что следует с осторожностью воспринимать информацию, получаемую в социальных сетях). Проведенные исследования показали, что наиболее эффективными стратегиями опровержения являлись взаимосвязанность, факт-чекинг и апелляция к кредитности источника [23].

Коррекция недостоверной информации будет более успешной в том случае, когда опровержение поступает из того же источника, что и она сама [24]. Кроме того, значимым является и уровень доверия к источнику недостоверной информации. Если этот уровень высок, то такую информацию довольно трудно опровергнуть.

Важную роль в успехе опровержения играет структура «опровергающего» сообщения [4]. Оно должно включать не только указание на то, что некоторая информация является ложной, но и аргументы в поддержку правильной точки зрения. Только при наличии таких аргументов опровержение оказывается успешным.

Эффективность опровержения недостоверной информации различается в зависимости от того, какая тема затрагивается [23]. Наиболее успешно бороться с подобной информацией удавалось в том случае, когда она касалась медицины. Если же фейки затрагивали вопросы политики или маркетинга, то их опровержение было менее успешным. Такого рода результаты, по-видимому, обусловлены различиями в субъективной значимости темы для человека и характере взаимосвязи недостоверного представления с другими психологическими образованиями личности.

Частоту повторения недостоверной информации и время, прошедшее между ее появлением и опровержением, также следует принимать в расчет при коррекции несоответствующих реальности представлений. Чем 
больше это время и чем чаще недостоверная информация повторялась, тем слабее оказывается действие опровержения [6].

Важную роль при опровержении недостоверной информации играет направление когнитивной активности человека - получателя «опровергающего» сообщения [5]. Наибольшая эффективность опровержения достигалась в тех случаях, когда при помощи специальных приемов (например, наводящих вопросов) удавалось побудить человека «хорошенько задуматься» о приводимых ему доказательствах ложности некоторого представления. Если же подобной активности не было (или она была направлена на ложную точку зрения и подтверждающие ее факты), то эффективность опровержения существенно снижалась.

Таким образом, успешное опровержение должно как побуждать человека к обдумыванию сообщаемых ему аргументов в поддержку верного представления, так и препятствовать рассуждениям, затрагивающих основания ложного. Дело в том, что в процессе углубленной когнитивной обработки проходит интеграция новой информации в структуру представлений человека о мире, формируется новая ментальная модель (или корректируется уже существующая), касающейся определенного аспекта реальности [9]. Если же когнитивная активность при получении сообщения с опровержением отсутствует, то, скорее всего, старая, основанная на недостоверной информации модель продолжит свое существование.

Установлено, что значимое влияние на эффективность опровержения недостоверной информации оказывают аттитюды и представления человека - реципиента такой информации. Хотя на первый взгляд кажется, что опровержение направлено на коррекцию частного и обособленного представления о мире, однако реагиру- ет на него целостная личность.

Как известно, уже существующие у человека аттитюды и убеждения во многом определяют его когнитивную активность при взаимодействии с окружающим миром. В частности, речь идет о склонности к подтверждению своей точки зрения или предвзятости (confirmation bias) - тенденции человека отдавать предпочтение такой информации, которая согласуется с уже сформировавшейся у него позицией [20]. Предвзятость приводит к поляризации суждений и появлению групп людей, для которых характерно доминирование одной точки зрения и закрытость по отношению к противоречащим ей фактам и мнениям.

Ощутимое влияние на эффективность опровержения недостоверной информации оказывают аттитюды и убеждения, связанные с ее темой. Например, при опровержении фейков, касающихся политики, значимую роль играют политические взгляды (политическая идеология) человека [23].

Проведенные исследования показали, что несмотря на наличие многообразных психологических механизмов, усиливающих интерес человека к недостоверной информации, посредством различных стратегий опровержения можно успешно защищать личность от ее воздействия. К факторам, повышающим эффективность противодействия такой информации относятся: вид стратегии опровержения, особенности источника недостоверной информации и субъекта, от которого исходило опровержение, структура опровергающего сообщения, затрагиваемая им тема, частота повторения недостоверной информации и время, прошедшее между ее появлением и опровержением, степень и направление когнитивной активности реципиента, его аттитюды и убеждения.

\section{ЛИТЕРАТУРА}

1. Berger, J., Milkman, K. What makes online content viral? // Journal of Marketing. 2012. V. 49. P. 192-205.

2. Bronstein, M., Pennycook, G., Bear, A., Rand, D.G., Cannon, T. Belief in fake news is associated with delusionality, dogmatism, religious fundamentalism, and reduced analytic thinking // Journal of Applied Research in Memory and Cognition. 2018. V. 8. P. 108-117.

3. Busselle, R. Schema theory and mental models // Rossler, P. (Ed.), The international encyclopedia of media effects. Hoboken, NJ: Wiley-Blackwell. 2017. P. 1753-1760.

4. Cappella, J. N., Maloney, E., Ophir, Y., Brennan, E. Interventions to correct misinformation about tobacco products // Tobacco Regulatory Science. 2015. V.1. P. 186-197.

5. Chan, M.P.S., Jones, C.R., Hall Jamieson, K., Albarracín, D. Debunking: A meta-analysis of the psychological efficacy of messages countering misinformation // Psychological Science. 2017. V. 28. P. 1531-1546.

6. Ecker, U.K., Lewandowsky, S., Cheung, C.S., Maybery, M.T. He did it! She did it! No, she did not! Multiple causal explanations and the continued influence of misinformation // Journal of Memory and Language. 2015. V. 85. P. 101-115.

7. Ecker, U.K., Lewandowsky, S., Swire, B., Chang, D. Correcting false information in memory: Manipulating the strength of misinformation encoding and its retraction // Psychonomic Bulletin \& Review. 2011. V.18. P. 570-578. 
8. Goreis, A., Voracek, M. A systematic review and meta-analysis of psychological research on conspiracy beliefs: Field characteristics, measurement instruments, and associations with personality traits // Frontiers in psychology. 2019. V. 10. 205. URL: https://doi.org/10.3389/fpsyg.2019.00205 (дата 0бращения: 30.10.2020).

9. Hart, W., Albarracín, D., Eagly, A.H., Brechan, I., Lindberg, M.J., Merrill, L. Feeling validated versus being correct: A meta-analysis of selective exposure to information // Psychological Bulletin. 2009. V. 135. P. 555-588.

10. Hollander, B.A. Partisanship, individual differences, and news media exposure as predictors of conspiracy beliefs // Journalism and Mass Communication Quarterly. 2017. V. 95. P. 691-713.

11. Kumar, S., Shah, N. False information on web and social media: a survey // arXiv preprint arXiv: 1804.08559. 2018. URL: https://arxiv.org/pdf/1804.08559.pdf (дата обращения: 30.10.2020).

12. Lahrach, Y., Furnham, A. Are modern health worries associated with medical conspiracy theories? // Journal of Psychosomatic Research. 2017. V. 99. P. 89-94.

13. Lewandowsky, S., Ecker, U.K. H., Seifert, C.M., Schwarz, N., Cook, J. Misinformation and its correction: Continued influence and successful debiasing // Psychological Science in the Public Interest. 2012. V. 13. P.106-131.

14. Nyhan, B., Reifler, J. When corrections fail: The persistence of political misperceptions // Political Behavior. 2010. V. 32. P. 303-330.

15. Oliver, J.E., Wood, T.J.. Conspiracy Theories and the Paranoid Style(s) of Mass Opinion // American Journal of Political Science. 2014. V. 58. P. $952-966$.

16. Orosz, G., Krek,ó, P., Paskuj, B., Tóth-Király, I., Bothe, B., Roland-Lévy, C. Changing conspiracy beliefs through rationality and ridiculing // Frontiers in psychology. 2016. V. 7. URL: https://core.ac.uk/download/pdf/82849353.pdf (дата обращения: 30.10.2020).

17. Pennycook, G., Rand, D.G. Who falls for fake news? The roles of bullshit receptivity, overclaiming, familiarity, and analytic thinking // Journal of Personality. 2020. URL: https://onlinelibrary.wiley.com/doi/full/10.1111/jopy.12476 (дата обращения: 30.10.2020).

18. Pérez-Rosas, V., Kleinberg, B., Lefevre, A. Mihalcea, R. Automatic detection of fake news // ArXiv. 2017. Preprint arXiv:1708.07104. URL: https://arxiv.org/ pdf/1708.07104.pdf (дата обращения: 30.10.2020).

19. Richey, S. A Birther and a truther: the influence of the authoritarian personality on conspiracy beliefs // Politics and Policy. 2017. V. 45. P. 465-485.

20. Sude, D.J., Knobloch-Westerwick, S., Robinson, M.J., Westerwick, A. “Pick and choose” opinion climate: How browsing of political messages shapes public opinion perceptions and attitudes // Communication Monographs, 2019. V. 86. N 4. P. 1-22.

21. Uenal, F. The "Secret Islamization" of Europe: exploring integrated threat theory for predicting Islamophobic conspiracy stereotypes // International Journal of Conflict and Violence. 2016. V. 10. P. 93-108.

22. Vosoughi, S., Roy, D., Aral, S. The spread of true and false news online // Science. 2018. V. 359. P. 1146-1151.

23. Walter, N., Murphy, S.T. How to unring the bell: A meta-analytic approach to correction of misinformation // Communication Monographs. 2018. V. 85. P. 423-441.

24. Walter, N., Tukachinsky, R. A meta-analytic examination of the continued influence of misinformation in the face of correction: How powerful is it, why does it happen, and how to stop it? // Communication Research. 2019. URL: https://doi.org/10.1177/0093650219854600 (дата обращения: 30.10.2020).

(с) Латынов Владислав Викторович (vladlat5@lenta.ru).

Журнал «Современная наука: актуальные проблемы теории и практики»

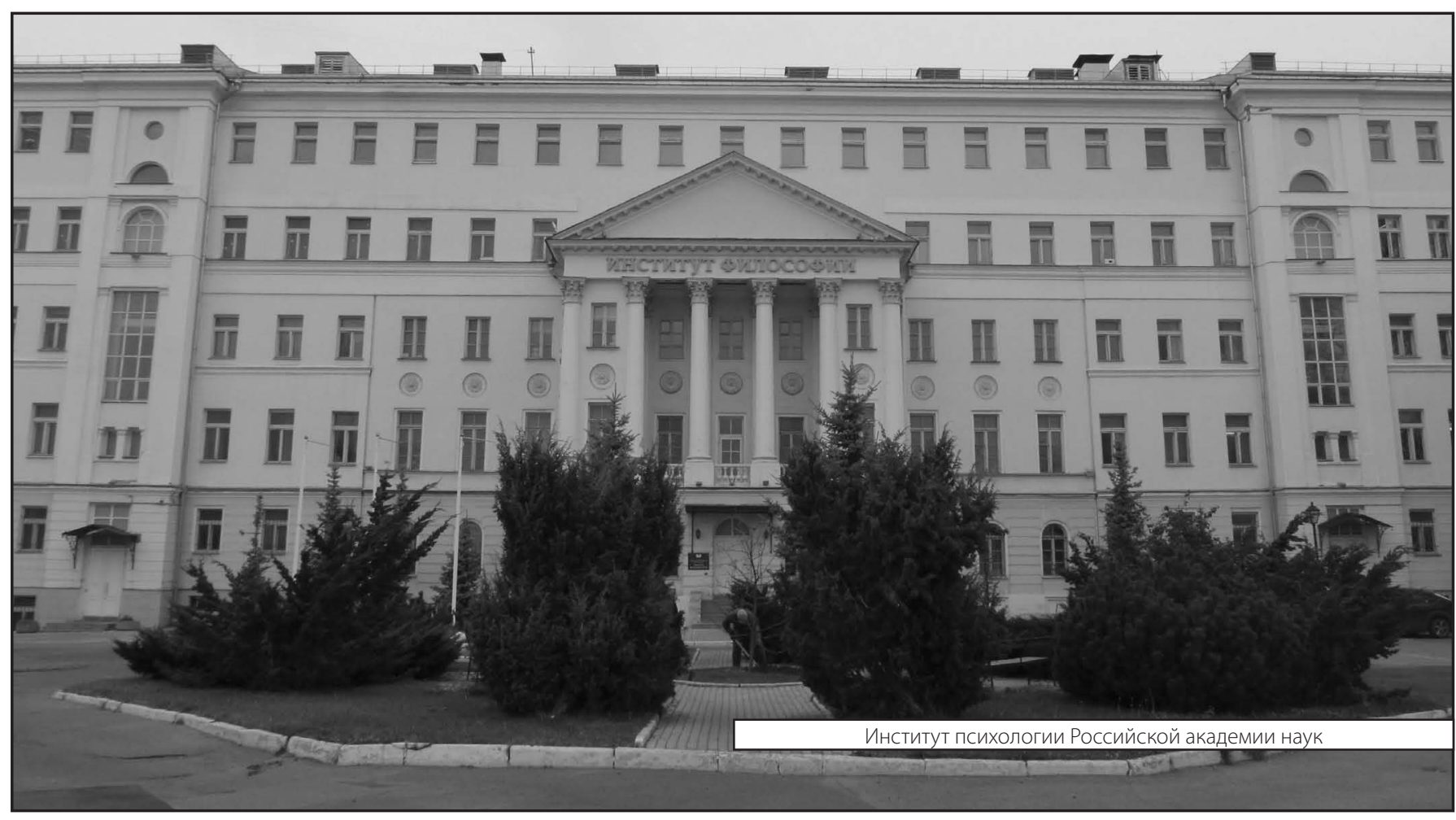

